\title{
Blockchain: Future of e-Governance in Smart Cities
}

\author{
Abhirup Khanna ${ }^{1, *} \mathbb{0}$, Anushree Sah ${ }^{1, *}$, Vadim Bolshev ${ }^{2,3, *} \mathbb{0}$, Michal Jasinski ${ }^{4} \mathbb{D}$, Alexander Vinogradov ${ }^{2}$, \\ Zbigniew Leonowicz ${ }^{4}\left(\mathbb{D}\right.$ and Marek Jasiński ${ }^{5}$ (D)
}

1 School of Computer Science, University of Petroleum and Energy Studies, Dehradun 248007, India

2 Laboratory of Power Supply and Heat Supply, Federal Scientific Agroengineering Center VIM, Moscow 109428, Russia; schkolamolen@gmail.com

3 Laboratory of Intelligent Agricultural Machines and Complexes, Don State Technical University, Rostov-on-Don 344000, Russia

4 Department of Electrical Engineering Fundamentals, Faculty of Electrical Engineering, Wroclaw University of Science and Technology, 50-370 Wroclaw, Poland; michal.jasinski@pwr.edu.pl (M.J.); zbigniew.leonowicz@pwr.edu.pl (Z.L.)

5 WWSIS “Horyzont", 54-239 Wrocław, Poland; jasinski.lubin@gmail.com

* Correspondence: abhirupkhanna@yahoo.com (A.K.); asah@ddn.upes.ac.in (A.S.); vadimbolshev@gmail.com (V.B.)

Citation: Khanna, A.; Sah, A.; Bolshev, V.; Jasinski, M.; Vinogradov, A.; Leonowicz, Z.; Jasiński, M. Blockchain: Future of e-Governance in Smart Cities. Sustainability 2021, 13, 11840. https://doi.org/10.3390/ su132111840

Academic Editor: Cheolho Yoon

Received: 30 September 2021

Accepted: 21 October 2021

Published: 26 October 2021

Publisher's Note: MDPI stays neutral with regard to jurisdictional claims in published maps and institutional affiliations.

Copyright: (c) 2021 by the authors. Licensee MDPI, Basel, Switzerland. This article is an open access article distributed under the terms and conditions of the Creative Commons Attribution (CC BY) license (https:/ / creativecommons.org/licenses/by/ $4.0 /)$.

\begin{abstract}
In recent times, Blockchain has emerged as a transformational technology with the ability to disrupt and evolve multiple domains. As a decentralized, immutable distributed ledger, Blockchain technology is one of the most recent entrants to the comprehensive ideology of Smart Cities. The rise of urbanization and increased citizen participation have led to various technology integrations in our present-day cities. For cities to become smart, we need standard frameworks and procedures for integrating technology, citizens and governments. In this paper, we explore the potential of Blockchain technology as an enabler for e-governance in smart cities. We examine the daily challenges of citizens and compare them with the benefits being offered by Blockchain integration. On the basis of a comprehensive literature review, we identified four key areas of e-governance wherein Blockchain can provide monumental advantages. In the context of Blockchain integration for e-governance, the paper presents a survey of prominent published works discussing various urban applications.
\end{abstract}

Keywords: Blockchain; IoT; e-governance; smart cities; urban planning

\section{Introduction}

Blockchain is decentralized, secure, auditable and enables smart execution of transactions. It is a distributed ledger where data are shared over a peer-to-peer network securely and consistently. Blockchain technology is presently one of the most quickly developing technologies and is reasonable for most applications. Blockchain is a circulated framework; there are no specific delegates between the users. In this way, manufacturers can manage their clients in a straightforward manner. Trust is an innate segment of these business connections as it is necessary to be confided in the stakeholders and market. To accomplish the transactions using Blockchain, the executive's objectives are cost, quality, speed, reliability, risk decrease, supportability and adaptability disintermediation or bypassing agents guarantees are done, yet it is not very clear that Blockchain will have these impacts on all types of industry and that it will perform all tasks well [1].

Blockchain technology means both positive and negative effects on the business world. With the assistance of Blockchain, business activities in smart cities have changed a large amount. Developing Advancements have additionally influenced smart city executives. The advent of Blockchain technology offers greater spatial and temporary flexibility. New technologies bring jobs, production and marketing closer together, and encourage major change through rethinking, redesigning and rebuilding cities and their functions. Blockchain technology is influencing almost all the areas of the market, such as in the 
globalized creation and the circulation of agri-business formation Blockchain reestablished center around the security, quality and the approval of a few significant rules in agricultural (horticulture) and food supply chains. The developing worries about sanitation and defilement chances have re-established the concentration on upgraded recognizability over the flexible food supply chain [2]. Ongoing innovations and advancements with Blockchain can give an important and useful arrangement ensuring detectability of farming produce and removes the requirement for a confided-in incorporated position. Today, Blockchain technology is used in various cities of the world and it is growing day by day and, today, all the smart cities are being made with the help of this technology. The reason for the growth of this technology is that it helps in reducing our effort and saves a lot of time. In the current scenario, sometimes Blockchain anchor is alluded to as a troublesome technology and it has potential to change the present business measures, which we are as of now utilizing, or it can interfere with advancement cycles and change plans of action drastically. The following are some of the prominent contributions of our work:

- A systematic review of Blockchain technology with respect to Smart Cities;

- Exemplifying prominent works discussing the application of Blockchain technology in e-governance for Smart Cities;

- Detailed bibliometric analysis across five real-world application areas of e-governance

- A structured overview and description of publication patterns for the use of complimenting technologies such as AI, Cloud and IoT for the creation of Smart Cities

The rest of the paper is organized as follows. Section 2 talks about smart cities and their relevance and architectures. In Section 3, we discuss types of Blockchain implementations along with some of the popular consensus algorithms. The emergence of smart cities has given rise to various aspects of e-governance in terms of citizen participation and government initiatives, which are illustrated in Section 4. Section 5 presents the benefits of Blockchain integration with smart cities and explores ways in which it plays a pivotal role in the creation and sustenance of smart cities. Notable works concerning application areas of Blockchain in e-governance are discussed in Section 6. In Section 7, we describe our research methodology and present a detailed bibliometric analysis based upon existing academic literature. Finally, Section 8 summarizes our findings and concludes the work.

\section{Smart Cities}

The concept of smart cities discusses ways in which new age urban development can be initiated to ensure efficiency of operations and enhanced citizen participation. It is an umbrella term comprising of a combination of multiple technologies of the likes of Blockchain, IoT, AI and Cloud computing. The rise of smart cities was seen as a necessity to counter challenges appearing from rapidly growing populations. In generalized terms, smart cities involve integration of information technologies and applications of new age innovations with various aspects of an urban infrastructure. A smart city comprises the following four pillars at an infrastructure level: Social Infrastructure, Physical Infrastructure, Institutional Infrastructure and Economic Infrastructure [3]. The degree of smartness for a city depends upon various factors such as its ability to accommodate social, economic and environmental needs along with enhancing the Quality of Life for its citizens. Smart cities are a new paradigm for facilitating the citizen with high-quality facilities with improving management and use of resources. A smart city is a way of providing the best services and improving the day-to-day life of citizens [4]. Smart cities improve their healthcare, transport, education, consumption of energy, waste management, e-governance, agriculture, supply chain management, etc., for the benefit of people. The concept of the smart city is still evolving, and many security concerns come with them. Therefore, Blockchain, with properties such as decentralized, secure, auditable, reliability, etc., has the potential to develop smart cities. One of the key aspects of creating a smart city involves the development of infrastructure. Smart homes and smart buildings constitute a majority of the infrastructure in smart cities. The creation of smart homes and buildings involves significant use of networked sensors and IoT technologies [5]. Researchers across the world have 
emphasized the use of IoT, Wireless Sensor Networks and Cloud integration for enabling the creation of smart cities. Blockchain is the newest entrant to the list of technologies that can facilitate the creation of energy efficient smart cities. The fusion of Blockchain and IoT (BIoT) is one of the leading research areas of our time and finds applicability from creating smart hospitals to designing smart transportation systems [6]. Table 1 talks about various application areas that focus on the use of IoT in creating smart cities. Even though the concept of smart cities seems enticing to many, its development has numerous challenges, the establishment of robust network infrastructure, privacy protection and social inclusiveness, to name a few. Blockchain technology, with its characteristics, provides state of the art solutions to major concerns of smart cities [7]. Blockchain helps in making cities fully digitalized, where each and every thing will be digitally controlled and, because of this feature, it reduces human effort and saves a lot of time. Blockchain, in combination with IoT, helps in enhancing transparency, establishing trust, improving convivence of infrastructure and efficiency of operations in a smart city. One study [8] sheds light on different areas such as healthcare, transport, education, consumption of energy, waste management, agriculture, etc., of smart cities where Blockchain can be applied. Similar to Blockchain and IoT, Artificial Intelligence (AI) is an upcoming technology, gaining widespread attraction from researchers with respect to application development for various verticals in a smart city. Table 2 is a reflection of the same, discussing different areas of AI implementation. Through the extensive research of Blockchain technology in smart cities, some research directions are also identified which are discussed later. Figure 1 showcases the impact areas of Blockchain technology in smart cities.

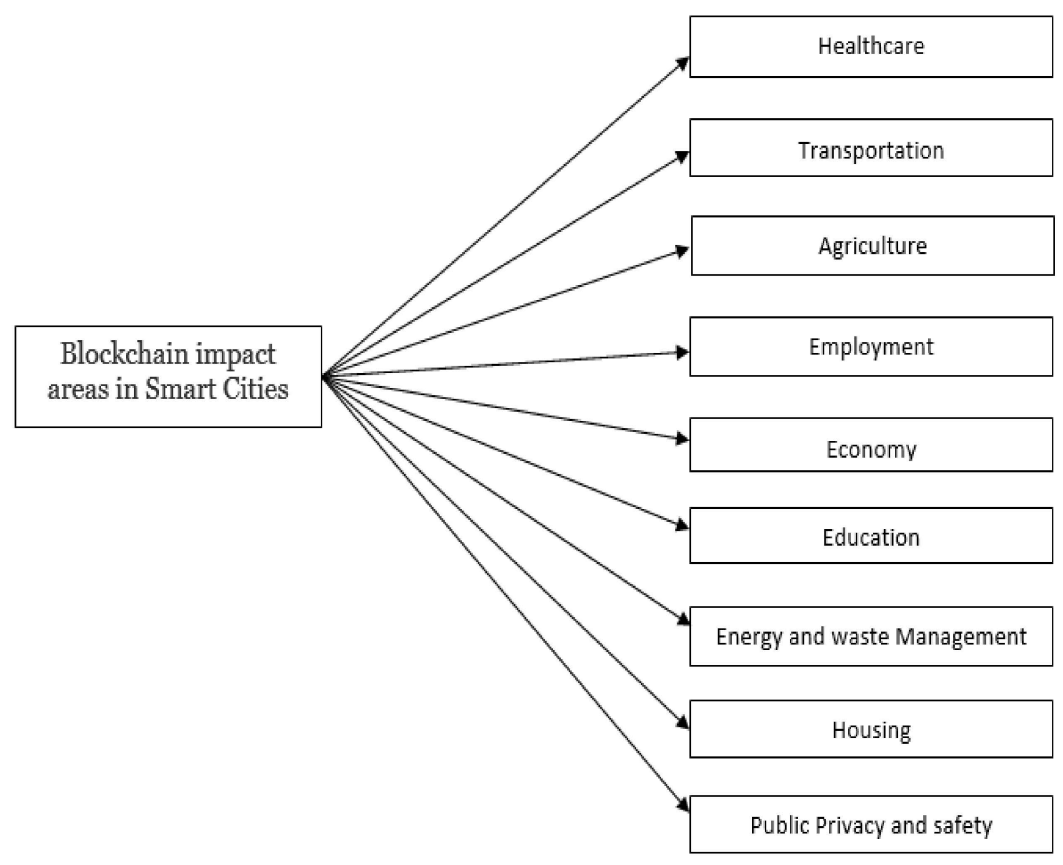

Figure 1. Blockchain impact areas in smart cities.

The reason for using Blockchain technology in smart cities is that is it very much useful in various kinds of operations, for example, it helps in making transactions easier as well as much simpler [9]. Some advantages of using Blockchain technology in smart cities are:

- It provides security for our data;

- It can help in waste collection and can provide real-time information;

- It may also be useful in trading electricity;

- It also helps in mobility and can provide real-time data to the governments;

- It makes communication easier;

- It helps in improving city connectivity. 
Table 1. IoT application areas in Smart Cities.

\begin{tabular}{cc}
\hline Theme & Publications \\
\hline IIoT & {$[10-15]$} \\
Smart Homes & {$[16-20]$} \\
Waste Management & {$[21-27]$} \\
Smart Parking & {$[28-31]$} \\
Smart Lighting & {$[32-34]$} \\
\hline
\end{tabular}

Table 2. AI application areas in Smart Cities.

\begin{tabular}{cc}
\hline Theme & Publications \\
\hline Traffic Management & {$[35-40]$} \\
Environment Monitoring & {$[41-44]$} \\
Energy Efficiency & {$[45-50]$} \\
Banking \& Finance & {$[51-55]$} \\
Agriculture & {$[56-63]$} \\
\hline
\end{tabular}

\section{Introduction to Blockchain}

Blockchain technology is gaining popularity every day and, with recent advancements, it will gain popularity. The integral part of Blockchain architecture is transactions, Blocks and consensus. Consensus is the way of using Blockchain in which Blockchain transactions are verified. There are different consensus methods attached to different Blockchains. Everyone in the network follows the rules of consensus algorithms such as, for bitcoin, Proof of Work (POW) is used and for Ethereum, Proof of Stake (PoS) is used. Similarly, different other types of consensus algorithms will be discussed in this section.

\subsection{Types of Blockchians}

The Public Blockchain is a publicly accessible Blockchain that can be termed as a public Blockchain. The main advantage of this Blockchain is its uncontrollability, which means that nobody will have complete control over the network. This type of Blockchain helps in the immutability of records [64]. Examples of a public Blockchain are Bitcoin and Ethereum. These are open-source Blockchains and have a focus on accessibility. Bitcoin is an example of this Blockchain that can be used in a real-life scenario. This type of Blockchain allows everyone equal access and also allows them to be anonymous while making transactions over the network. One of the advantages of a public Blockchain is security. The more dynamic and decentralized a public Blockchain is, the safer it becomes. In addition, there are a greater number of individuals that work on the system; therefore, it becomes more difficult for the threat to be successful. It is almost inconceivable for hackers to rally and jeopardize the network. One more advantage is that public Blockchain is transparent. All information identified with exchanges is available to the public. The straightforwardness of public Blockchain expands potential use cases. Perhaps the most serious issue with public Blockchain is speed. One of the Public Blockchains, Bitcoin is amazingly lethargic. Scalability and energy consumption are the concern in a public Blockchain.

As the name suggests, private Blockchain requires the participant to be invited before they can be part of Blockchains. Here, all the transactions are visible only for a person who is part of the Blockchain. These Blockchains are centralized, as a small group controls the Blockchain. These are used in a private organization to store sensitive data. A private Blockchain is also called a permissioned Blockchain. Examples of such Blockchain are Hyperledger and Ripple. Business-to-business scenarios and corporations, internally, use Private Blockchain. Private Blockchains are lighter and throughput is higher because of the lesser number of transactions done than for public Blockchain. In private Blockchain, only approved peers are allowed to take part in the system, and therefore the level of access is limited. Private Blockchains are more defenseless to the dangers of hacks and breaks 
because of the way that a couple of players control the system. These couple of approved players can manipulate the system as well.

The consortium Blockchain can be of two types: some nodes private; other nodes public. This type of Blockchain comes out to be an ideal Blockchain between private and public. In consortium, the Blockchain network is managed and maintained by more than one organization, it is sort of semi-decentralized type of Blockchain. It has high efficiency compared to a public Blockchain. It relishes the advantages of both private and public Blockchain. It becomes a hybrid Blockchain if an organization wants to deploy the best of both public and private Blockchains [65]. Since there is no single power overseeing the control, it keeps up with the decentralized nature of the Blockchain. A consortium Blockchain is also called federated Blockchain where no single organization governs it and, instead, a group or an organization governs the Blockchain. A consortium Blockchain is most appropriate for associations where there is a requirement for the two kinds of Blockchains, i.e., public and private. A consortium Blockchain is private, but more than one party governs the decision power and, therefore, it is less centralized than a private Blockchain. A consortium Blockchain is faster as compared to a public Blockchain, as access is specific to few users not to all. Consortium Blockchain has low transaction costs and is scalable. It is safer and energy-efficient as well. Examples of such a type of Blockchain are IBM Food Trust and Energy Web Foundation.

\subsection{Consesus Algorithms}

Consensus algorithms are one of the most important parts of Blockchain technology, as they make sure transactions are safe and secure. Therefore, now, in this research article, we will be discussing a few famous consensus algorithms.

Proof-of-Work is a consensus algorithm and is a decentralized Blockchain network. Its concept was introduced for securing digital money. Proof-of-Work came into existence with Bitcoin and makes use of SHA-256 hashing algorithms. Proof-of-Work also forms the basis of cryptocurrency. Previously, it was used in the mining of cryptocurrencies and was used for mining new tokens and also for validation of transactions. In Proof-of-Work, miners validate transactions and the hash code of new blocks has to be identified and then it is needed to be added to a network, whosoever finds the node will be given the others. Proof-of-Work algorithm of Blockchain demands higher requirements of hardware and also uses extreme computational power. Bitcoin uses the Proof-of-Work algorithm to generate new tokens and to validate transactions. Similar to Bitcoin, Ethereum also uses a Proof-of-Work consensus algorithm which makes sure that all the information recorded is safe from all kinds of monetary attacks. All the information of nodes is recorded in the Ethereum Blockchain. As the technology evolves, Proof-of-Work algorithms will be obsolete and Proof-of-stake (PoS) will be favored.

Proof-of-Stake uses the concept of rewarding the nodes that have more coins, and this algorithm is a second-generation Blockchain network. Proof-of-Stake requires lesser power consumption as compared to Proof-of-Work. This algorithm is the substitute for the Proof-of-Work algorithm and is safer. The proof-of-Stake algorithm is environmentally sustainable and is scalable to the needs of the user. Proof-of-Stake substitutes staking for power consumption during computation. In addition, it limits the peers mining power with the percentage of ownership. Ethereum now uses the Proof-of-Stake algorithm that works on the concept that the more tokens you have the more is the power of mining. This algorithm uses fewer resources but the chances of $51 \%$ attack are more and, also, the chances of keeping tokens and not using them. The largest cryptocurrency, i.e., Bitcoin, is still Proof-of-Work but debates and research are underway to move it to the Proof-ofStake model.

Delegated Proof-of-Stake is an evolved and advanced type of Proof-of-Stake where nodes selection is of a different type. It allows coin holders to take part in the consensus method. Coin holders can choose to select the node or reject it. A delegated Proof-of-Stake algorithm is more suited for the network that is established and is trusted. The process 
of delegation and voting is the democratic type in Delegated Proof-of-Stake. Delegated Proof-of-Stake is a fairer method of picking who confirms the following block, permitting a more different group of individuals to partake in the process since it depends on procured status as a legitimate staker and not generally just wealthy. Also, because there are a predetermined number of validators, Delegated Proof-of-Stake permits the network to arrive at an agreement all the more rapidly.

The Practical Byzantine Fault Tolerance algorithm is a high performance and is advanced with high latency and amazing overhead runtime. Essentially, every one of the nodes in the Practical Byzantine Fault Tolerance model is requested in a succession with one node being the leader node and the others mentioned as the backup nodes. Nodes inside the network speak with one another and the objective is for every one of the genuine nodes to obtain a settlement on the condition of the network through popularity. Nodes speak with one another vigorously, and do not just need to demonstrate that messages came from a particular companion node; yet, in addition, it is required to check that the message was not altered during transmission. Hyperledger Fabric is an open-source platform for Blockchain activities and innovations. Hyperledger uses the permission form of the Practical Byzantine Fault Tolerance algorithm. Other well-renowned organizations that use the Practical Byzantine Fault Tolerance algorithm are Ripple and Stellar.

\section{Rise of e-Governance \& Smart Cities}

E-governance in smart cities is a type of governance that aims to make effective use of information and communication technology (ICT) to improve services provided by the government to people and will increase participation in decision-making and policy formulation. This will improve governance and advance the digital transformation of government. The smart city concept of e-Gov 2.0 in India promotes a holistic approach to local urban development. Globally, smart cities are emerging like mushrooms after rain, and it is difficult to provide the best convenience facilities for locals in urban areas. In the Indian context, the role of self-government is very important and logical. Although E-governance supports a people-oriented service-oriented concept, the local development of smart cities is also people-oriented [66].

E-governance (Electronic governance) has the aim of enhancing government ability. E-governance is used to provide services to citizens, interact with business enterprises and is used to do communicate with speed, efficiently and in a transparent manner. The basic purpose of e-governance is to simplify processes. E-governance has many benefits. Some of them are that it will make corruption less common because all transactions are done on the internet so the data are recorded. Because of e-governance, the communication gap is reduced. E-governance has reduced overall cost. E-governance aims to improve the quality of governance. E-governance ensures the participation of people in governing processes. With the help of e-governance, we are doing local, state and nation's elections smoothly by machines. It is saving our time, money and preventing the stealing of votes. A smart city is a technology-modern urban area that is using different types of electronic media and sensors to collect specific data. Smart cities make more efficient use of infrastructure through Artificial Intelligence. Smart cities make less use of time for citizens. Smart cities are safer cities. Technologies such as license plate recognition and gunshot detectors can make a criminal-free city. Smart cities will help to reduce the environmental footprint. Smart cities make the transport system better.

The rise in population has caused a great amount of burden on the civic amenities and the administrative infrastructure making e-governance an important part of managing the administration of almost all of the countries over the world. Talking about India, the initiatives that have been taken for e-governance have to meet two requirements- the first being automating the government departments and the second being making the online services easily understandable and accessible to civilians. The growth of e-governance over the past few years has shown the active participation of citizens in the strategic schemes of the government. E-governance has also resulted in showing the "efficiency, accountability 
and the transparency" of these schemes. According to the UNITED NATIONS, the objective and the reason behind e-governance is to provide and make the citizens aware of the government departments and their information by means of the internet and the worldwide-web. Another example of e-governance can be shown in the times of the COVID-19 pandemic, where the maximum amount of governance and administration was done in an online mode. Even the vaccination was done the means of an app and online portal where people came to know about the number of vacant slots available so that they could book a slot for their vaccination. After the booking was completed, they were notified regarding the time and place where their vaccination was going to be conducted [67].

Smart cities are also a part of e-governance. The concept of a smart city originated in the US and was implemented in the 1990s. Since then, it has been evolving along with humans at every stage. Smart cities have spread out wide and have been included in policymaking to provide the solutions to "urban dimensions" which include the governments, infrastructure, environments, citizens and economy. In today's world, with the increase in the manufacture of vehicles, there has been an increase in the traffic in the country. The number of cars on the roads have been more than the number of people sitting on them. The never decreasing traffic has caused people to be late for their work and other destinations, and manufactured goods take more time than estimated to reach shop owners. Mobility is a concept of smart cities, which counters the current problem of traffic. The mobility concept is also known as smart mobility, and is different from the transport of people and goods in general. Mobility can be considered an integral part of smart cities and can be described as a set of measures coordinated to improve the efficiency and the environmental sustainability of cities. The most important feature of mobility is interconnectivity. This feature of interconnectivity, when combined with the shared data, requires passengers to access and transmit their own data to get an idea of the situation on the roads. By the means of smart applications that are available, the passengers are able to know about traffic conditions, whether there have been any accidents on the roads, avoiding bottlenecks and the amount of time they will take to reach their destination, as well choosing a particular route and then providing the alternative to the route and the number of free parking spaces that are available. These applications also show the available restaurants, grocery stores, petrol pumps and charging stations that the passengers may have on their routes. The popular examples of these applications include navigation, e-tickets, parking tickets, e-tolls, information boards, autonomous vehicles and shared mobility services-such as shared cycles, cars, scooters, etc.

The increasing progress and demand of technology has changed various domains of the social life of a person-how he/she works, interacts with the people and his/her consumption and production of data. Technical innovations are the core of the smart city, making them able to build an efficient and urban environment. Gradually, the urban systems are including the ideas of smart cities and working for technological advancement. One such urban system being energy. The smart energy city comes from the energy-related components of a city. The smart energy city makes use of the opportunities in the technical field and available technology and economy to improve the life of the people. It also tends to confront the challenges faced in climate change, energy resources and infrastructure.

Blockchain can bring significant improvements in the traditional business models in terms of transparency, security and traceability. E-governance is a part of Information and Communication Technologies (ICT). It works to enhance communications, increase efficiency and transparency and keep the proper record of everything. E-governance would also help the government to collect the right data of all people, as they would have all the necessary info such as ID number and many more. Moreover, this would help in reducing crime, for example fraud. The government could also analyze data and know many things such as how many people are underprivileged in their country and how many rich people are not paying proper taxes, among many more applications. It helps to establish a connection between governments, government and businesses, government and citizens and agencies of two governments. With the benefits, there comes some disadvantages too, 
such as the old citizens of the country could not be able to utilize the resources properly as they might have difficulty in learning anything new. Secondly, it would also result in an information leak if somehow the server where the information is stored were hacked, and it would reveal secret information about our country to other countries. It would also cost a lot for the government to establish good servers with good security.

\section{Benefits of Blockchain Implementation in Smart Cities}

The integration of business models with Blockchain improves transparency, security, trust, cost minimization, accountability and efficiency. Blockchain-enabled contracts bring rising levels of efficiency to smart cities [62]. To impact changes in other specialized fields, Blockchain technology can be combined with technologies such as Smart cities, Big Data, IoT and Artificial Intelligence. Benefits of implementing Blockchain in smart cities are securing the supply chain, creating transparency, boosting track and trace systems, automating the purchase process and more streamlined operations.

Agriculture is the backbone of most developing countries and the means for most of their revenue, as crops are supplied to other countries to meet their demands and sometimes these sent crops prove contaminated, deliver late, etc., which directly affects the trade. Therefore, [24] suggests the use of Ethereum Blockchain and smart contracts for better traceability of the whole soybean process from the production of seed to the product delivery; the whole process is centralized in nature and eliminates the middlemen. For future work, they argue that it is necessary work on flaws related to scalability, governance, identity registration and privacy, as well as that the payment mode should be restructured where parties will be paid using cryptocurrency on successful physical delivery of products by the smart contracts in an automated and centralized manner.

However, the implementation of Blockchain technology may look simple, but it is difficult to implement, as it is not yet fully developed. There is a need for highly skilled professionals and the collaborative participation of people to build a common system. It is challenging to answer how Blockchain brings more value to smart cities management and organizations as Blockchain is not a Distributed Computing System. Scalability is also an issue in the Blockchain. Some Blockchain solutions consume too much energy and Blockchain transactions are sometimes inefficient. Also, it is not completely secure to use.

A Blockchain-based smart city has many limitations, it yields high integrity but has unstable information reliability without some form of independent or impartial system that can manage or check the integrity of data going into the Blockchain [68]. A Blockchainbased smart city can offer transparency and trust to its citizens, and this trust and transparency are as valuable as the reliability of the raw data fed into the system and the way it is further treated [69]. Further, [70] tells us about the benefits of the implementation of IoT and Blockchain together. We all know how important IoT is nowadays, however, IoT has some problems related to privacy and security which can be overcome by integrating Blockchain technology. This results in improved efficiency in smart cities networks, and thus gives us a transparent view of a system. Many people are not aware of the Blockchain, so it is often implemented on a large scale [7]. This article will help in knowing about Blockchain and its implementation in smart cities.

Blockchain can connect technologies that can be helpful for people in many ways. The more we use this technology the more benefit we can derive from it. Blockchain has the ability and potential to make things easier to use and access. This is has led to creating many small and big networks as well. Therefore, there are many such applications of Blockchain that can be implemented in cities:

- $\quad$ Easy and smart payments: Blockchain provides security when performing payments and requests are sent to the respective virtual machines while performing the payments. In addition, it continually updates the information regarding the payments and maintains a proper history; 
- Identity Services: nowadays, many organizations use this technology for identification purposes. They use unique login services and authenticate personal identity using the same, which helps prevent identity theft and fraud;

- Transportation Management: provides a single link of payment for various forms of public transport, which includes ridesharing services. A person using a taxi and bus can pay through a single-mode using Blockchain technology;

- Government Services: it helps in maintaining a proper record of documents and identity information of the citizens. This technology will enable the delivery of focused and personalized government services.

\section{Application Areas of Blockchain in e-Governance}

The concept of e-governance comprises ways in which governments can govern and serve their citizens in the best possible manner through the use of new-age technologies. It promotes enhanced citizen participation and has gained widespread attention in the last decade. In this digital age, we have numerous technologies that can act as an enabler for e-governance. The newest entrant to the club is Blockchain technology, proving a decentralized peer-to-peer platform for trust and transparency. In recent years, multiple government agencies have adopted the use of Blockchain technology for rendering citizen-centric services. The distributed ledger technology allows individuals to conduct transactions in a secure and automated manner. In this section, we address the question of how Blockchain technology can mitigate the challenges of modern cities and facilitate the development of urban ecosystems. We carry out a comprehensive literature review and identify five key application areas of e-governance wherein Blockchain has emerged as an enabler technology. The section illustrates prominent works for (1) Energy Trading, (2) Smart Healthcare, (3) e-voting, (4) Supply Chain and (5) Real Estate. Table 3 summarizes some of the prominent works for the above application areas.

Table 3. Blockchain Application Areas for e-Gov \& Smart Cities.

\begin{tabular}{lcc}
\hline & Theme & Publications \\
\hline & Energy Trading & {$[31,71-77]$} \\
Smart Healthcare & {$[78-85]$} \\
Blockchain \& e-governance & e-voting & {$[86-90]$} \\
& Supply Chain & {$[91-98]$} \\
& Real Estate & {$[99-105]$} \\
\hline
\end{tabular}

\subsection{Energy Trading}

In recent years, Blockchain has emerged as a leading technology for creating peerto-peer energy trading platforms. Such trading systems prove beneficial for consumers and producers as they can directly trade energy without the need for an intermediatory. The immutable ledger technology has been termed by researchers as a "disruptive technology" in the field of energy trading. In the recent past, numerous start-ups have emerged presenting Blockchain-enabled solutions for energy management in a smart city environment. The solutions ensure trading fairness, ensure accurate billing cycles, mitigate intermediary costs, preserve user data privacy and facilitate automatic trades. The authors propose a decentralized platform for peer-to-peer energy trading and ensure a trade-off between economic efficiency and information privacy [71]. The work discusses a two-layered platform for the Ant-Colony Optimization method for auctioning and smart contracts for enabling faster trade settlements. The proposed decentralized platform is termed "DeMarket" and aims for prosumers to auction and trade electricity securely and efficiently. The platform uses digital tokens, called "EuroTokens," to ensure monetary settlements for trading purposes. According to the existing literature, Blockchain and IoT are favourable technologies that can be combined to create decentralized energy trading platforms. The authors highlight pertinent issues dealing with centralized trading platforms for distributed energy stations (DESs). A Blockchain-based electricity trading 
(B-ET) ecosystem is proposed that ensures payment security and privacy protection for energy trading transactions [72]. The proposed ecosystem comprises two subsystems namely Internet-of-Energy (IoE) subsystem and the Blockchain subsystem. The prior is used for connecting various distributed energy stations across the city whereas the latter ensures secure and reliable electricity trading by the use of smart contracts. The authors propose a new consensus mechanism named credit-based PoW, which is a modified version of the widely implemented Proof-of-Work (PoW) consensus algorithm. The newly proposed consensus algorithm is believed to have mitigated the challenges of high latency and randomness.

Smart transportation is one of the central areas to the concept of smart cities. On similar lines to ensuring intelligent management of energy systems, the authors propose a decentralized peer-to-peer (P2P) smart city energy model for interconnecting households and enabling energy trading among themselves [73]. The work aims to optimize the energy management of a city by collating neighbouring households and allowing energy surplus of them to trade their electricity using smart contracts. All interconnected households are collectively termed as a microgrid, which is connected to the Blockchain network for trading electricity with potential consumers. The proposed models make use of wireless sensor networks for monitoring the generation, transmission and consumption of electricity on a real-time basis. The native cryptocurrency of Ethereum, i.e., Ether (ETH), is used for ensuring monetary settlements. The Particle Swarm Optimization (PSO) algorithm coupled with a genetic algorithm is used for the efficient selection of source and destination nodes for electricity transmission. A relatable initiative for decentralized P2P energy trading is proposed by the authors for mitigating the imbalance of energy generation among various users in a community [74]. The Blockchain-enabled trading platform is a decentralized application (dApp) that uses Ethereum's smart contract for ensuring transactions. The rise of electric vehicles (EVs) and Connected Electric Vehicles (CEVs) propose enhanced safety, improved city governance and reduced dependency on oil and emission of greenhouse gases. It is believed that the concept of CEV can give rise to new business models for energy trading and decentralize the process of electricity distribution. The authors propose a decentralized electricity trading framework for CEVs that combines the implementation of Blockchain, machine learning and game theory [75]. The work discusses an adaptive bidding algorithm named "HLProfitX" for ensuring improved profitability during the sale and purchase of electricity. A new cryptocurrency Happy Light Coin (HLCoin) is introduced for ensuring monetary settlements.

\subsection{Smart Healthcare}

The authors present a decentralized Blockchain-enabled platform "GuardHealth" for patient data sharing [78]. The platform deals with sensitive information regarding a patient, thus ensuring confidentiality and data privacy. The proposed system uses a consortium Blockchain network for storing and sharing patient data through legitimate authentication. On similar lines of patient data sharing, the authors present a combination of secure file transfer methods and Blockchain technology [79]. The model ensures secure patient data sharing across various clinical facilities of its visit. Blockchain and IoT are extremely complementing technologies and are being extensively used across various domains. In context to the same, the authors propose an architecture for combining the use of Blockchain technology and the Internet of Medical Things (IoMT). The work analyses the current challenges of IoMT and suggests ways of mitigating them using smart contracts and distributed ledger [80]. Blockchain is a huge success when it comes to its applicability for creating identity management systems. The authors propose a Blockchainenabled identity management system for patients and healthcare professionals [81]. Each patient and healthcare professional are allotted a unique health ID for ensuring their secure identification and authentication across different eHealth domains. Every health ID is attested by a healthcare regulator and subsequently stored on the Blockchain network. Another example of storing patient-centric records using Blockchain is presented by the 
authors wherein they propose a telemedical laboratory service for performing clinical trials on patients through IoT medical devices [82].

\section{3. e-Voting}

In recent times, e-voting has emerged as one of the most prominent application areas of Blockchain technology in e-governance. The characteristics of being decentralized, transparent, secure and anonymous makes Blockchain one of the most suitable technologies for conducting free and fair elections in modern democracies [86]. Blockchain has the potential to ensure the integrity of the entire electoral process. It is believed that Blockchainenabled e-voting systems can mitigate the challenges of conventional voting systems [87]. Such challenges may comprise accurate voter identification, protection of voter privacy, the secure casting of votes and efficient vote counting. Countries such as India, Estonia and South Korea are working towards creating models for e-voting using Blockchain technology [88].

\subsection{Supply Chain}

Blockchain has seen significant success in the financial sector and, subsequently, researchers have started to explore its applicability across supply chain management [91]. A supply chain is a system comprising of various entities intended to deliver a particular product or service manufacturer to a customer. Conventional supply chains are centralized in nature, thus present numerous challenges of corruption, mishandling, product tampering and adulteration. Blockchain has emerged as a disruptive technology with the potential to change the working mechanisms of modern-day supply chains [92]. The distributed ledger technology presents transparency and real-time tracking of product flow across various checkpoints [93]. The authors explore various ways of integrating Blockchain into supply chain management systems [94]. The integration of blockchain with supply chain management can bring about considerable benefits in terms of cost-efficiency, reliability, traceability and reduced paperwork [95]. Moreover, the food industry is believed to be one of the biggest benefits of the applicability of Blockchain technology in supply chains [96]. Blockchain coupled with IoT proves to be a perfect combination for food supply chains and ensuring trust and identification of counterfeit products [97].

\subsection{Real Estate}

The real estate sector has great socio-economic value to the nation. One of the emerging application areas of Blockchain technology in e-governance is real estate and asset registration [99]. Blockchain facilities fast and secure transactions through smart contracts between two parties in a verifiable manner. Researchers and developers are gaining interest in creating architectures and frameworks for Blockchain-enabled land registry systems [100]. The systems are secure, transparent and support functionates of transfer of ownership and mortgage registration. Integration with Blockchain technology with the real estate sector ensures trust and reliability in keeping land records and supports national wealth creation [101]. Blockchain has the potential to improve the slow and inefficient real estate sector and eliminate unnecessary manual processes [102]. Concerns relating to loss or duplication of documents can be easily mitigated [103]. Due to the absence of intermediaries, Blockchain technology can reduce the cost of asset registries by a significant value [104]. Moreover, illegal or shadow real estate transactions can be identified and stopped by the use of Blockchain technology [105].

\section{Literature Survey}

\subsection{Methodology}

The paper follows a multi-step research methodology for analyzing publishing patterns in the field of Blockchain technology e-governance and smart cities. The survey was conducted based on the Scopus database [106]. Articles published between 2017 and 2021 were considered for the survey. During the process of publication search, we ensured that 
the papers selected were written in the English language. The primary step involved searching publications based on keywords such as "Blockchain AND Smart Cities" \& "Blockchain AND e-Governance". We ensured that the keywords were mentioned in either the paper's abstract or title. The results of the first step led to the identification of five prominent application areas wherein Blockchain finds its maximum applicability in e-governance. The subsequent step involved searching publications based on the identified application areas. The final step of the publication search involved identifying complementing technologies for Blockchain. Through this effort, we were able to list three key technologies that complement and support Blockchain in modernizing present-day cities. The analysis part of the survey focused on three dimensions which led to enhanced insights concerning the research being conducted in Blockchain technology and Smart Cities. The following are the sets of keywords that were searched during our survey:

1. Smart city or smart cities (SC);

2. Blockchain $+\mathrm{SC}$;

3. Blockchain + e-governance;

4. Blockchain $+\mathrm{SC}+$ Smart Healthcare;

5. Blockchain $+\mathrm{SC}+$ e-voting;

6. Blockchain $+\mathrm{SC}+$ Energy Trading;

7. Blockchain $+\mathrm{SC}+$ Supply Chain;

8. Blockchain $+\mathrm{SC}+$ Real Estate;

9. Blockchain $+\mathrm{SC}+($ IoT or Internet of Things);

10. Blockchain $+\mathrm{SC}+\mathrm{AI}$;

11. Blockchain $+\mathrm{SC}+$ Cloud Computing.

\section{2. e-Gov vs. Smart Cities}

The following Figures 2 and 3 discusses the publication patterns for Smart Cities and e-Governance with respect to application of Blockchain technology.

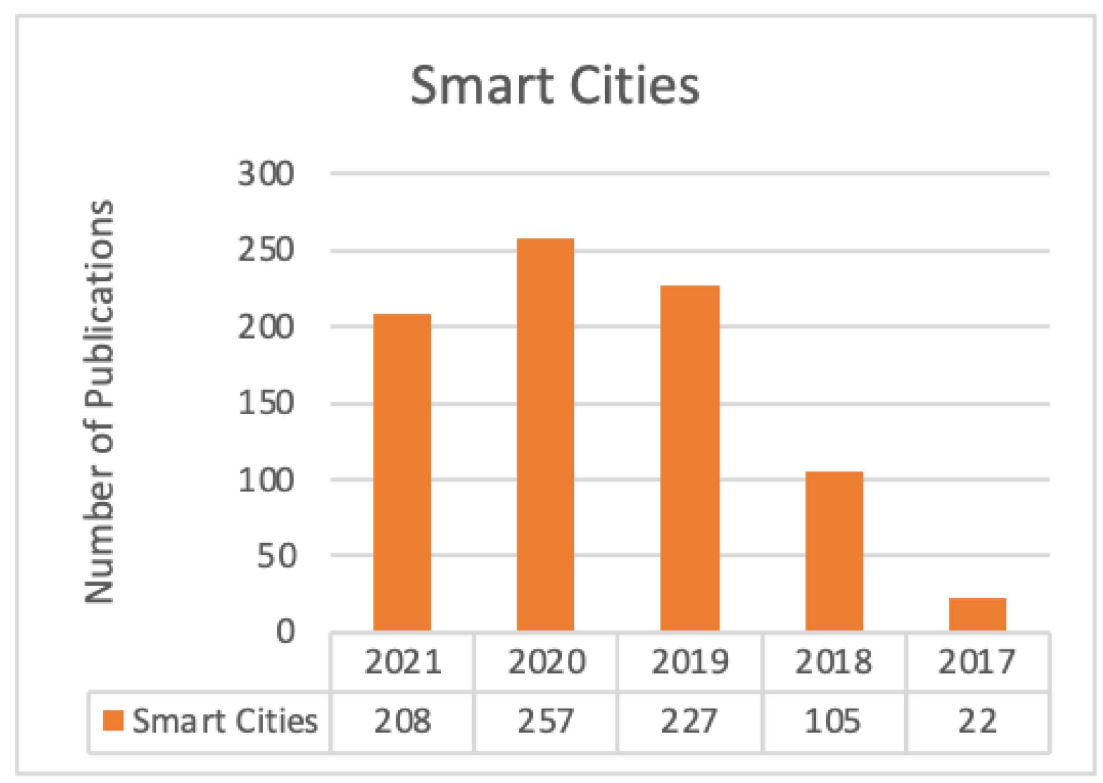

Figure 2. Publication Count Blockchain AND Smart Cities. 


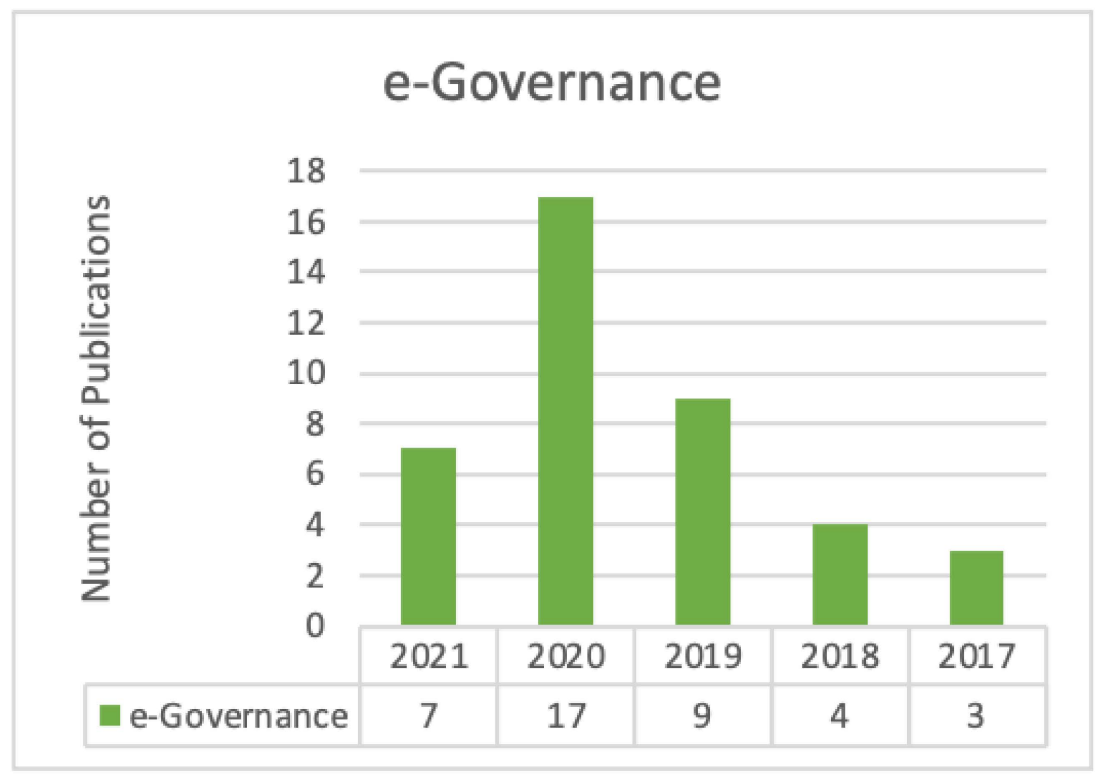

Figure 3. Publication Count Blockchain AND e-governance.

\subsection{Blockchain Application Areas}

The following Figure 4 discusses year wise publication count with respect to prominent areas of Blockchain applicability in e-Governance in smart cities. Figure 5 talks about publication patterns in terms of nature of publications. Figures 6-9 illustrate region wise publication classifications for areas of Energy Trading, Smart Healthcare, Supply Chain and Real Estate in smart cities.

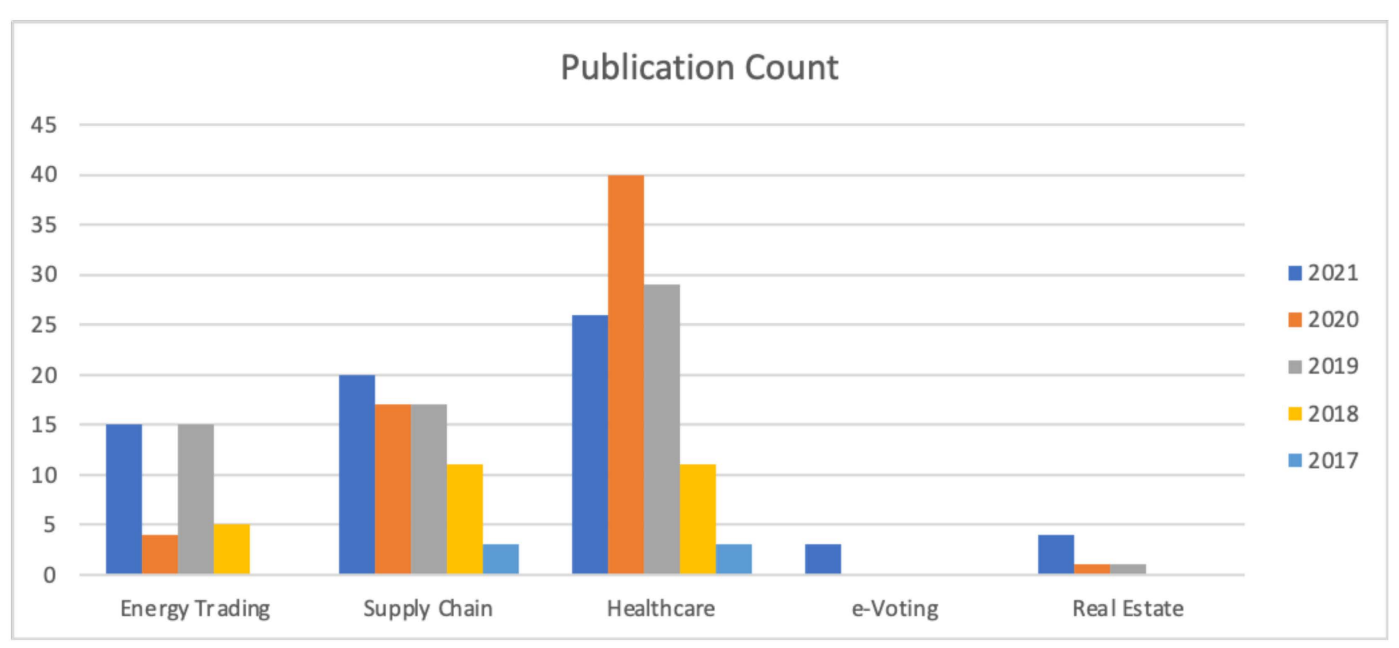

Figure 4. Publication Count comparison among application areas. 
Publication Classification

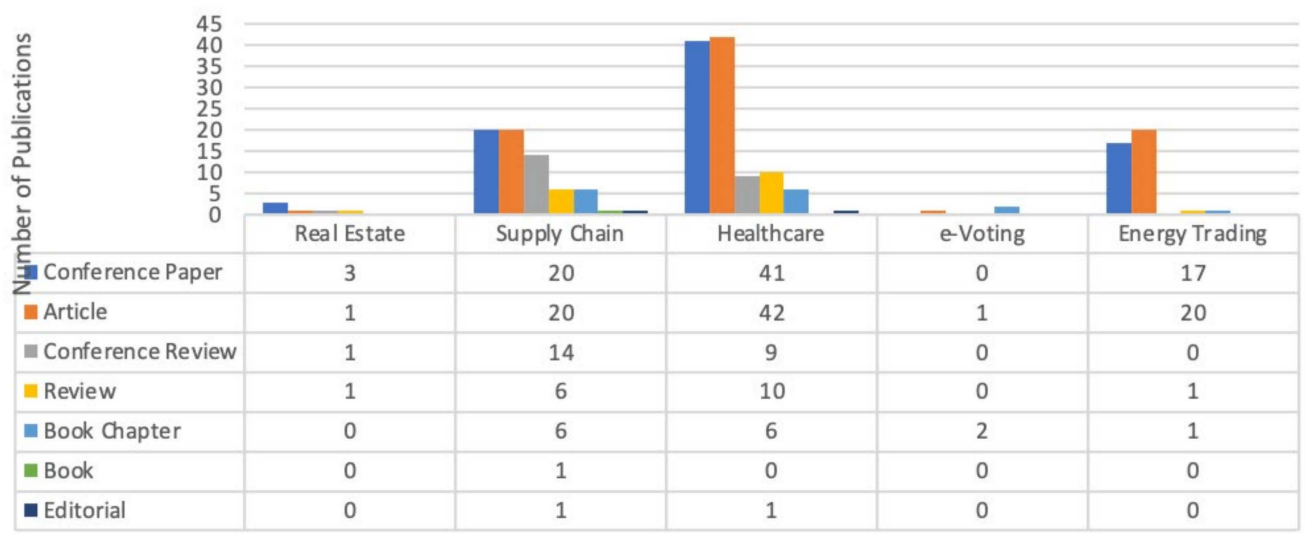

Figure 5. Publication classification comparison among application areas.

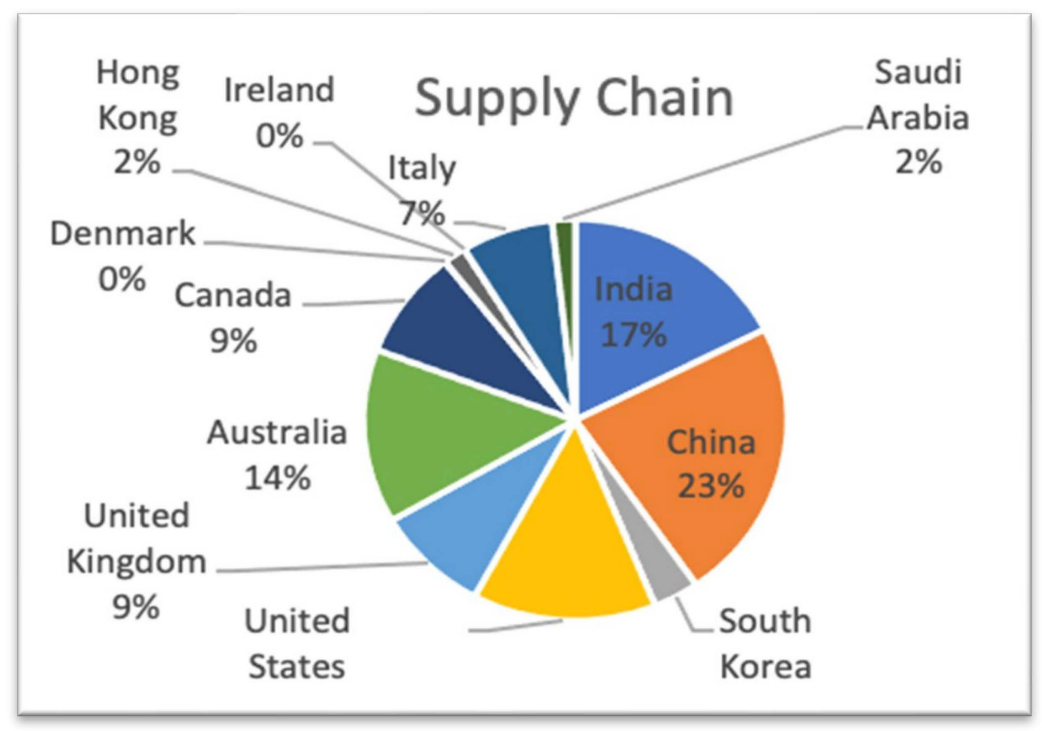

Figure 6. Region-specific publication distribution for Blockchain and Supply Chain.

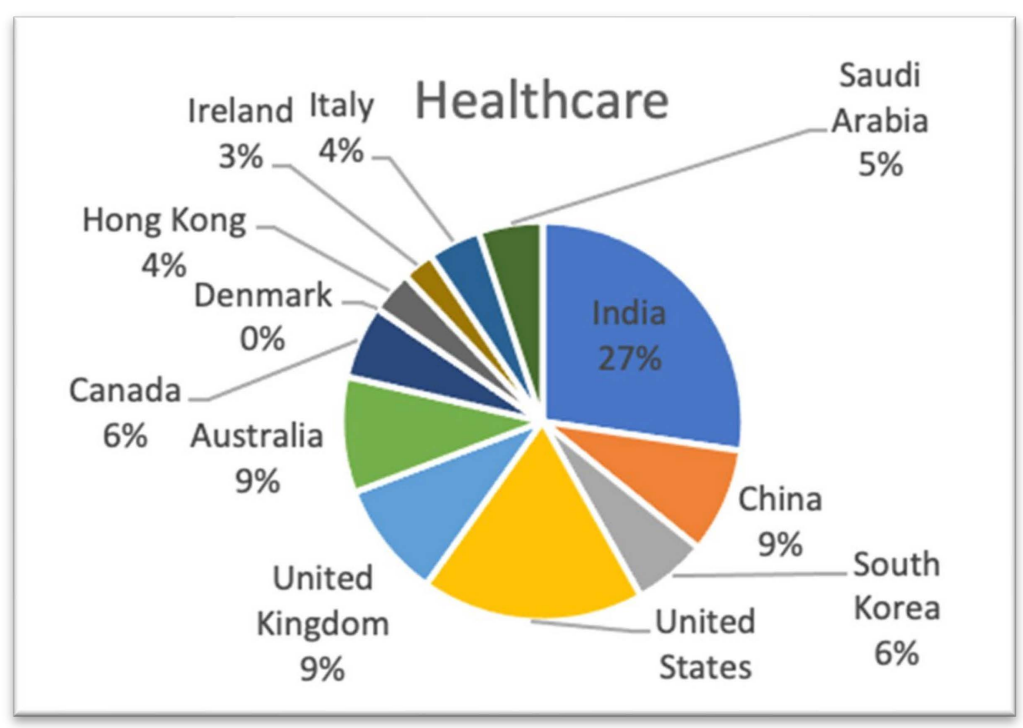

Figure 7. Region-specific publication distribution for Blockchain and Smart Healthcare. 


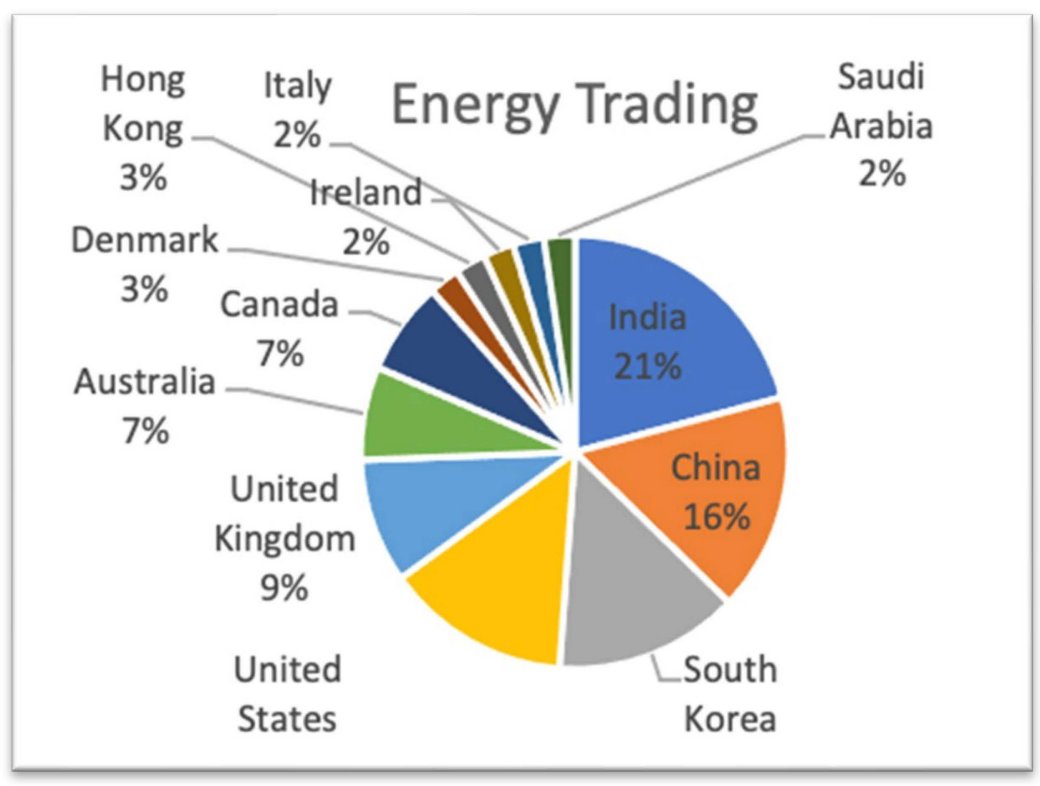

Figure 8. Region-specific publication distribution for Blockchain and Energy Trading.

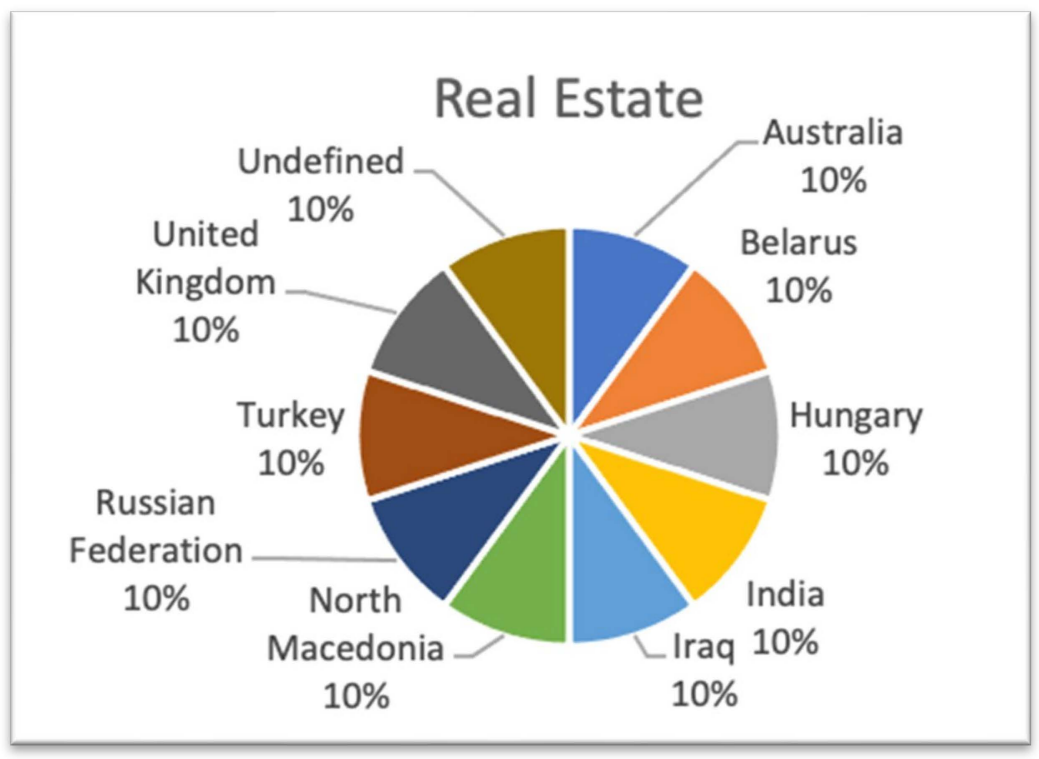

Figure 9. Region-specific publication distribution for Blockchain and Real Estate.

\subsection{Allied Technologies for Blockchain}

Figures 10-12 present bibliometric analysis for works discussing the use of complimenting technologies for Blockchain such as Cloud Computing, AI and IoT for enabling e-Governance in smart cities. 


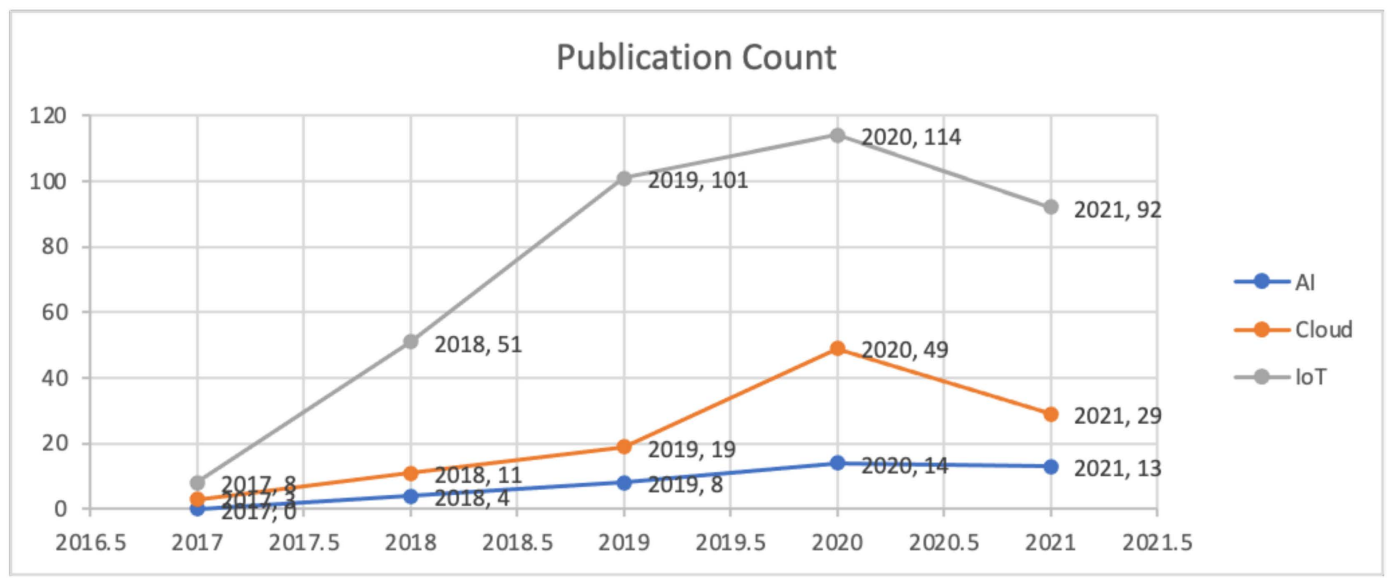

Figure 10. Year specific Publication Count comparison among complimenting technologies.

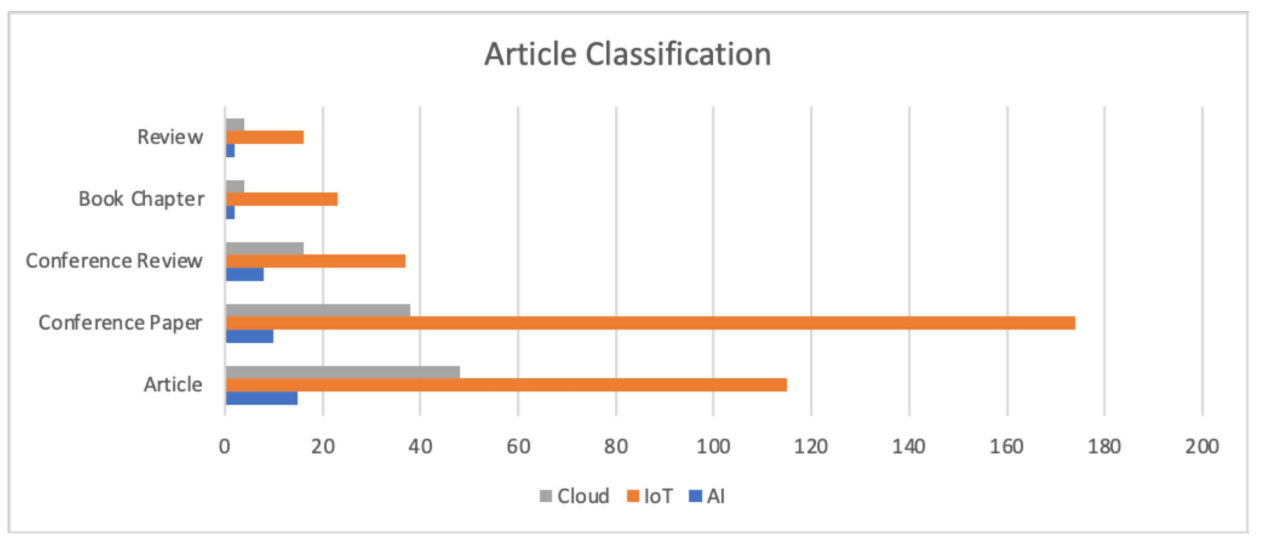

Figure 11. Publication classification comparison among complimenting technologies.

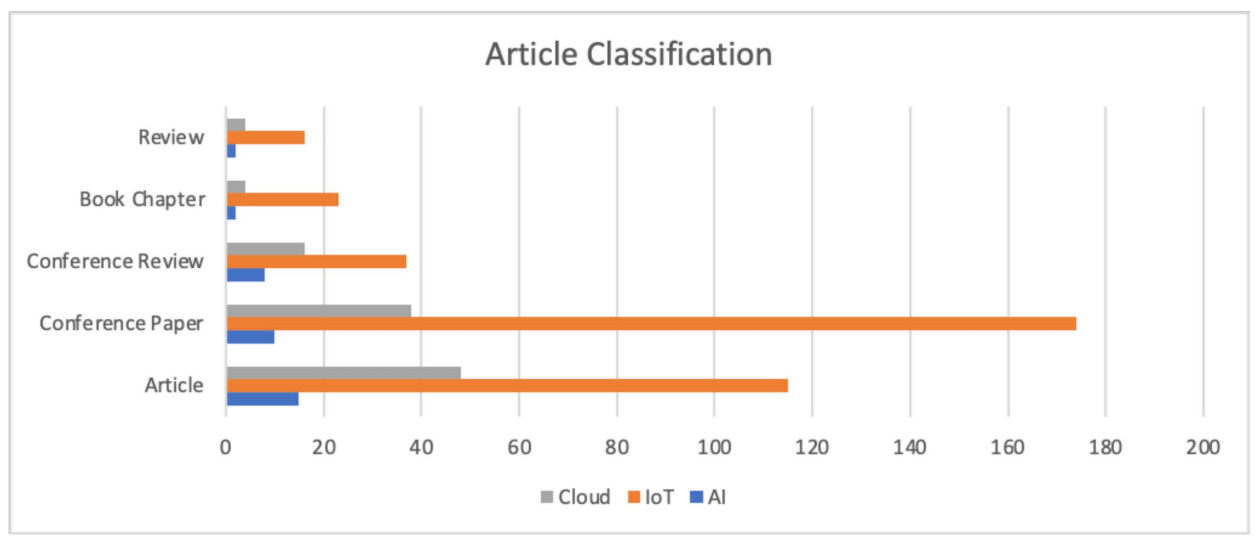

Figure 12. Region-specific publication distribution for complementing technologies.

\section{Discussion \& Conclusions}

Blockchain is one of the fastest emerging technologies which has started to see applicability beyond the financial sector. Its characteristics such as immutability, data traceability, security and decentralized nature have been the major driving factors for ensuring its success. In this article, we examine Blockchain as an enabler for smart cities. This work of ours aims to identify the extent of research that has been conducted in the last few years concerning Blockchain applicability for smart city governance. A detailed literature review 
is conducted to identify key application areas wherein Blockchain can prove beneficial and is likely to impact the governance of a smart city. The work assists academicians in understanding the findings of previous research and benefits from the following insights in crafting their research journey. Author Insights:

- New age disruptive technologies such as Blockchain, IoT, AI and Cloud can be combined together to render solutions for sustainable smart cities;

- Policymakers need to educate themselves with respect to Blockchain and understand the means and methods of its applicability across various areas of e-governance;

- Existing research suggests that countries have started working towards Blockchain integration in the form of pilot studies and, in years to come it will become a living reality;

- Emergence of Blockchain will eliminate the role of any third party intermediatory thus ensuring transparency, trust and growth in the economy;

- Blockchain integration with smart cities will give rise to new business models in domains of supply chain and energy trading. Individual citizens and government agencies will largely benefit economically from such new initiates;

- Citizen participation will see a significant rise in the decision-making process, thanks to the involvement of technologies such as Blockchain, IoT and AI. Higher levels of automation can be expected in decision making and problem solving;

- Overall, Blockchain will introduce a new sense of trust, transparency and security between citizens and governments.

Talking of future research directions, researchers can aim towards creating Blockchain applications supporting scalable transactions along with ensuring optimum levels of energy consumption. Applications of DeFi (Decentralized finance) for smart cities is another domain area for researchers to explore. Supply chain applications for perishable food items such as fruits and vegetables are an upcoming application area where new models can be proposed.

Author Contributions: Conceptualization, A.K.; methodology, A.K. and M.J. (Michal Jasinski).; software, A.S.; validation, V.B. and M.J. (Michal Jasinski).; formal analysis, A.V. and M.J. (Michal Jasinski).; investigation, A.K., A.S. and V.B.; resources, Z.L. and M.J. (Marek Jasiński); data curation, A.K. and A.S.; writing — original draft preparation, A.K. and A.S.; writing—review and editing, V.B. and Mic. J.; visualization, A.S. and V.B.; supervision, A.V., Z.L. and M.J. (Marek Jasiński); project administration, A.K. and A.V.; funding acquisition, M.J. (Michal Jasinski). and Z.L. All authors have read and agreed to the published version of the manuscript.

Funding: This research received funding from the Chair of Electrical Engineering Fundamentals (K38W05D02), Wroclaw University of Technology, Wroclaw, Poland.

Institutional Review Board Statement: Not applicable.

Informed Consent Statement: Not applicable.

Data Availability Statement: Not applicable.

Conflicts of Interest: The authors declare no conflict of interest.

\section{References}

1. Farouk, A.; Alahmadi, A.; Ghose, S.; Mashatan, A. Blockchain platform for industrial healthcare: Vision and future opportunities. Comput. Commun. 2020, 154, 223-235. [CrossRef]

2. Feng, H.; Wang, X.; Duan, Y.; Zhang, J.; Zhang, X. Applying blockchain technology to improve agri-food traceability: A review of development methods, benefits and challenges. J. Clean. Prod. 2020, 260, 121031. [CrossRef]

3. Haque, A.K.M.B.; Bhushan, B.; Dhiman, G. Conceptualizing smart city applications: Requirements, architecture, security issues, and emerging trends. Expert Syst. 2021. [CrossRef]

4. Bhushan, B.; Sinha, P.; Sagayam, K.M.; Andrew, J. Untangling blockchain technology: A survey on state of the art, security threats, privacy services, applications and future research directions. Comput. Electr. Eng. 2021, 90, 106897. [CrossRef] 
5. $\quad$ Bhushan, B.; Khamparia, A.; Sagayam, K.M.; Sharma, S.K.; Ahad, M.A.; Debnath, N.C. Blockchain for smart cities: A review of architectures, integration trends and future research directions. Sustain. Cities Soc. 2020, 61, 102360. [CrossRef]

6. Bhushan, B.; Sahoo, C.; Sinha, P.; Khamparia, A. Unification of Blockchain and Internet of Things (BIoT): Requirements, working model, challenges and future directions. Wirel. Netw. 2021, 27, 55-90. [CrossRef]

7. Rawat, S.; Sah, A. An approach to Enhance the software and services of Health care centre. IISTE 2012, 3, $126-137$.

8. Sah, A.; Dumka, A.; Rawat, S. Web Technology Systems Integration Using SOA and Web Services. In Handbook of Research on Contemporary Perspectives on Web-Based Systems; IGI Global: Hershey, PA, USA, 2018; pp. 24-45.

9. Dumka, A.; Sah, A. Smart ambulance traffic management system (SATMS) - A support for wearable and implantable medical devices. In Wearable and Implantable Medical Devices; Elsevier: Amsterdam, The Netherlands, 2020; pp. 215-228.

10. Ali, R.; Qadri, Y.A.; Bin Zikria, Y.; Al-Turjman, F.; Kim, B.-S.; Kim, S.W. A Blockchain Model for Trustworthiness in the Internet of Things (IoT)-Based Smart-Cities. In Trends in Cloud-Based IoT; EAI/Springer Innovations in Communication and Computing; Springer: Cham, Switzerland, 2020; pp. 1-19. [CrossRef]

11. Rathee, G.; Ahmad, F.; Sandhu, R.; Kerrache, C.A.; Azad, M.A. On the design and implementation of a secure blockchain-based hybrid framework for Industrial Internet-of-Things. Inf. Process. Manag. 2021, 58, 102526. [CrossRef]

12. Babbar, H.; Rani, S.; Singh, A.; Abd-Elnaby, M.; Choi, B.J. Cloud Based Smart City Services for Industrial Internet of Things in Software-Defined Networking. Sustainability 2021, 13, 8910. [CrossRef]

13. Khattak, H.A.; Tehreem, K.; Almogren, A.; Ameer, Z.; Din, I.U.; Adnan, M. Dynamic pricing in industrial internet of things: Blockchain application for energy management in smart cities. J. Inf. Secur. Appl. 2020, 55, 102615. [CrossRef]

14. Ashena, E. Evaluating a Blockchain-based Method for Industrial IoT Data Confidentiality: Proof of Concept. In Proceedings of the 2021 7th International Conference on Web Research (ICWR), Teheran, Iran, 19-20 May 2021; IEEE: Manhattan, NY, USA, $2021 ;$ pp. 260-266.

15. Perez Dominguez, L.A.; Contreas-Masse, R.; Ochoa-Zezzatti, A.; Garcia, V.; Elizondo-Cortes, M. Implementing a novel use of multicriteria decision analysis to select IIoT platforms for smart manufacturing. Symmetry 2020, 12, 368.

16. Umair, M.; Cheema, M.; Cheema, O.; Li, H.; Lu, H. Impact of COVID-19 on IoT Adoption in Healthcare, Smart Homes, Smart Buildings, Smart Cities, Transportation and Industrial IoT. Sensors 2021, 21, 3838. [CrossRef]

17. Ammi, M.; Alarabi, S.; Benkhelifa, E. Customized blockchain-based architecture for secure smart home for lightweight IoT. Inf. Process. Manag. 2021, 58, 102482. [CrossRef]

18. Yang, Q.; Wang, H. Privacy-Preserving Transactive Energy Management for IoT-aided Smart Homes via Blockchain. IEEE Internet Things J. 2021, 8, 11463-11475. [CrossRef]

19. Rajashree, S.; Sukumar, R. CBC (Cipher Block Chaining)-Based Authenticated Encryption for Securing Sensor Data in Smart Home. In Smart IoT for Research and Industry; Springer: Cham, Switzerland, 2022; pp. 189-204.

20. Kolahan, A.; Maadi, S.R.; Teymouri, Z.; Schenone, C. Blockchain-based solution for energy demand-side management of residential buildings. Sustain. Cities Soc. 2021, 75, 103316. [CrossRef]

21. Vamsi, T.M.N.; Chakravarthi, G.K.; Lanka, P.; Divakar, B. An IoT Based Smart Garbage Monitoring and Disposal Support System. In Proceedings of the 2021 5th International Conference on Computing Methodologies and Communication (ICCMC), Erode, India, 8-10 April 2021; IEEE: Manhattan, NY, USA, 2021; pp. 438-442.

22. Baldo, D.; Mecocci, A.; Parrino, S.; Peruzzi, G.; Pozzebon, A. A Multi-Layer LoRaWAN Infrastructure for Smart Waste Management. Sensors 2021, 21, 2600. [CrossRef]

23. Ramson, S.J.; Moni, D.J.; Vishnu, S.; Anagnostopoulos, T.; Kirubaraj, A.A.; Fan, X. An IoT-based bin level monitoring system for solid waste management. J. Mater. Cycles Waste Manag. 2021, 23, 516-525. [CrossRef]

24. Gopikumar, S.; Raja, S.; Robinson, Y.H.; Shanmuganathan, V.; Chang, H.; Rho, S. A method of landfill leachate management using internet of things for sustainable smart city development. Sustain. Cities Soc. 2021, 66, 102521. [CrossRef]

25. Dzhuguryan, T.; Deja, A. Sustainable Waste Management for a City Multifloor Manufacturing Cluster: A Framework for Designing a Smart Supply Chain. Sustainability 2021, 13, 1540. [CrossRef]

26. Gupta, Y.S.; Mukherjee, S.; Dutta, R.; Bhattacharya, S. A blockchain-based approach using smart contracts to develop a smart waste management system. Int. J. Environ. Sci. Technol. 2021, 1-24. [CrossRef]

27. Li, Z.; Alazab, M.; Garg, S.; Hossain, M.S. PriParkRec: Privacy-Preserving Decentralized Parking Recommendation Service. IEEE Trans. Veh. Technol. 2021, 70, 4037-4050. [CrossRef]

28. Badr, M.M.; Al Amiri, W.; Fouda, M.M.; Mahmoud, M.M.E.A.; Aljohani, A.J.; Alasmary, W. Smart Parking System With Privacy Preservation and Reputation Management Using Blockchain. IEEE Access 2020, 8, 150823-150843. [CrossRef]

29. Wang, S.M.; Cheng, W.M. Solve the Problem of Urban Parking Through Carpooling System and Blockchain Advertising. In International Conference on Human-Computer Interaction, Washington, DC, USA, 24-29 July 2021; Springer: Cham, Switzerland, 2021; pp. 144-155.

30. Kim, M.; Kim, Y. Multi-Blockchain Structure for a Crowdsensing-Based Smart Parking System. Futur. Internet 2020, 12, 90. [CrossRef]

31. Zhang, C.; Zhu, L.; Xu, C.; Sharif, K.; Wu, H.; Westermann, H. BSFP: Blockchain-Enabled Smart Parking With Fairness, Reliability and Privacy Protection. IEEE Trans. Veh. Technol. 2020, 69, 6578-6591. [CrossRef]

32. Gehlot, A.; Alshamrani, S.; Singh, R.; Rashid, M.; Akram, S.; AlGhamdi, A.; Albogamy, F. Internet of Things and Long-RangeBased Smart Lampposts for Illuminating Smart Cities. Sustainability 2021, 13, 6398. [CrossRef] 
33. Xu, W.; Kim, J.Y.; Huang, W.; Kanhere, S.; Jha, S.; Hu, W. EMIoT: A LoRa-enabled Smart Building Solution Based on Emergency Lights. In Proceedings of the 7th ACM International Conference on Systems for Energy-Efficient Buildings, Cities, and Transportation, Virtual Event, Japan, 18-20 November 2020; pp. 330-331.

34. Mishra, S.; Kumar, S. Smart Voltage Monitoring: Centralised and Blockchain-based Decentralised Approach. In Proceedings of the 2020 IEEE International Conference on Internet of Things and Intelligence System (IoTaIS), Bali, Indonesia, 27-28 January 2021; IEEE: Manhattan, NY, USA, 2021; pp. 49-55.

35. Soomro, S.; Miraz, M.H.; Prasanth, A.; Abdullah, M. Artificial Intelligence Enabled IoT: Traffic Congestion Reduction in Smart Cities. In Proceedings of the IET Conference, Manama, Bahrain, 22-23 April 2018; pp. 6-13. [CrossRef]

36. Cugurullo, F. Urban Artificial Intelligence: From Automation to Autonomy in the Smart City. Front. Sustain. Cities 2020, 2, 38. [CrossRef]

37. Lv, Z.; Lou, R.; Singh, A.K. AI Empowered Communication Systems for Intelligent Transportation Systems. IEEE Trans. Intell. Transp. Syst. 2021, 22, 4579-4587. [CrossRef]

38. Thanh, T.T.M.; Ly, H.B.; Pham, B.T. A Possibility of AI Application on Mode-choice Prediction of Transport Users in Hanoi. In CIGOS 2019, Innovation for Sustainable Infrastructure. Lecture Notes in Civil Engineering; Ha-Minh, C., Dao, D., Benboudjema, F., Derrible, S., Huynh, D., Tang, A., Eds.; Springer: Singapore; Volume 54. [CrossRef]

39. Hlaing, S.S.; Tin, M.M.; Khin, M.M.; Wai, P.P.; Sinha, G.R. Big Traffic Data Analytics For Smart Urban Intel-ligent Traffic System Using Machine Learning Techniques. In Proceedings of the 2020 IEEE 9th Global Conference on Consumer Electronics (GCCE), Kyoto, Japan, 12-15 October 2020; pp. 299-300.

40. Khanna, A.; Goyal, R.; Verma, M.; Joshi, D. Intelligent Traffic Management System for Smart Cities. In Proceedings of the International Conference on Futuristic Trends in Network and Communication Technologies, Chandigarh, India, 22-23 November 2019; Springer: Singapore, 2019; pp. 152-164.

41. Shaikh, R.A.J.; Naidu, H.; Kokate, P.A. Next-generation wsn for environmental monitoring employing big data ana-lytics, machine learning and artificial intelligence. In Evolutionary Computing and Mobile Sustainable Networks; Springer: Singapore, 2021; pp. 181-196.

42. Sunny, A.I.; Zhao, A.; Li, L.; Kanteh Sakiliba, S. Low-Cost IoT-Based Sensor System: A Case Study on Harsh Envi-ronmental Monitoring. Sensors 2021, 21, 214. [CrossRef]

43. Ye, Z.; Yang, J.; Zhong, N.; Tu, X.; Jia, J.; Wang, J. Tackling environmental challenges in pollution controls using artificial intelligence: A review. Sci. Total. Environ. 2020, 699, 134279. [CrossRef]

44. Ighalo, J.O.; Adeniyi, A.G.; Marques, G. Artificial intelligence for surface water quality monitoring and assessment: A systematic literature analysis. Model. Earth Syst. Environ. 2021, 7, 669-681. [CrossRef]

45. Selim, M.; Zhou, R.; Feng, W.; Quinsey, P. Estimating Energy Forecasting Uncertainty for Reliable AI Autonomous Smart Grid Design. Energies 2021, 14, 247. [CrossRef]

46. Lu, T.; Chen, X.; McElroy, M.B.; Nielsen, C.P.; Wu, Q.; Ai, Q. A Reinforcement Learning-Based Decision System for Electricity Pricing Plan Selection by Smart Grid End Users. IEEE Trans. Smart Grid 2021, 12, 2176-2187. [CrossRef]

47. ElHusseini, H.; Assi, C.; Moussa, B.; Attallah, R.; Ghrayeb, A. Blockchain, AI and Smart Grids: The Three Musketeers to a Decentralized EV Charging Infrastructure. IEEE Internet Things Mag. 2020, 3, 24-29. [CrossRef]

48. Kumar, N.M.; Chand, A.A.; Malvoni, M.; Prasad, K.A.; Mamun, K.A.; Islam, F.; Chopra, S.S. Distributed energy resources and the application of AI, IoT, and blockchain in smart grids. Energies 2020, 13, 5739. [CrossRef]

49. Singh, S.; Sharma, P.K.; Yoon, B.; Shojafar, M.; Cho, G.H.; Ra, I.-H. Convergence of blockchain and artificial intelligence in IoT network for the sustainable smart city. Sustain. Cities Soc. 2020, 63, 102364. [CrossRef]

50. Şerban, A.C.; Lytras, M.D. Artificial intelligence for smart renewable energy sector in europe-Smart energy infra-structures for next generation smart cities. IEEE Access 2020, 8, 77364-77377. [CrossRef]

51. Arslanian, H.; Fischer, F. The Future of Finance: The Impact of FinTech, AI, and Crypto on Financial Services; Springer: Singapore, 2019.

52. Max, R.; Kriebitz, A.; Von Websky, C. Ethical Considerations About the Implications of Artificial Intelligence in Finance. In International Handbooks in Business Ethics; Humana Press: Totowa, NJ, USA, 2021; pp. 577-592.

53. Mhlanga, D. Industry 4.0 in Finance: The Impact of Artificial Intelligence (AI) on Digital Financial Inclusion. Int. J. Financial Stud. 2020, 8, 45. [CrossRef]

54. Königstorfer, F.; Thalmann, S. Applications of Artificial Intelligence in commercial banks-A research agenda for behavioral finance. J. Behav. Exp. Financ. 2020, 27, 100352. [CrossRef]

55. Hassani, H.; Huang, X.; Silva, E. Big-Crypto: Big Data, Blockchain and Cryptocurrency. Big Data Cogn. Comput. 2018, 2, 34. [CrossRef]

56. Vincent, D.R.; Deepa, N.; Elavarasan, D.; Srinivasan, K.; Chauhdary, S.H.; Iwendi, C. Sensors driven AI-based agri-culture recommendation model for assessing land suitability. Sensors 2019, 19, 3667. [CrossRef]

57. Liu, S.Y. Artificial Intelligence (AI) in Agriculture. IT Prof. 2020, 22, 14-15. [CrossRef]

58. Alreshidi, E. Smart Sustainable Agriculture (SSA) Solution Underpinned by Internet of Things (IoT) and Artificial Intelligence (AI). Int. J. Adv. Comput. Sci. Appl. 2019, 10. [CrossRef]

59. Shadrin, D.; Menshchikov, A.; Somov, A.; Bornemann, G.; Hauslage, J.; Fedorov, M. Enabling Precision Agriculture Through Embedded Sensing With Artificial Intelligence. IEEE Trans. Instrum. Meas. 2020, 69, 4103-4113. [CrossRef] 
60. Sankaranarayanan, S. Applications of Artificial Intelligence for Smart Agriculture. In AI-Based Services for Smart Cities and Urban Infrastructure; Lyu, K., Hu, M., Du, J., Sugumaran, V., Eds.; IGI Global: Hershey, PA, USA, 2021; pp. 277-288. [CrossRef]

61. Bhardwaj, H.; Tomar, P.; Sakalle, A.; Sharma, U. Artificial Intelligence and Its Applications in Agriculture With the Future of Smart Agriculture Techniques. In Advances in Environmental Engineering and Green Technologies; IGI Global: Hershey, PA, USA, 2021; pp. 25-39.

62. Ragavi, B.; Pavithra, L.; Sandhiyadevi, P.; Mohanapriya, G.; Harikirubha, S. Smart Agriculture with AI Sensor by Using Agrobot. In Proceedings of the 2020 Fourth International Conference on Computing Methodologies and Communication (ICCMC), Erode, India, 11-13 March 2020; IEEE: Manhattan, NY, USA, 2020; pp. 1-4.

63. Ciruela-Lorenzo, A.M.; Del-Aguila-Obra, A.R.; Padilla-Meléndez, A.; Plaza-Angulo, J.J. Digitalization of Agri-Cooperatives in the Smart Agriculture Context. Proposal of a Digital Diagnosis Tool. Sustainability 2020, 12, 1325. [CrossRef]

64. Xu, L.; Li, Q.; Min, X.; Cui, L.; Xiao, Z. Collaborate Computing: Networking, Applications and Worksharing. In Proceedings of the 12th International Conference, CollaborateCom 2016, Beijing, China, 10-11 November 2016; Springer: Amsterdam, The Netherlands, 2017; pp. 490-496.

65. Negi, D.; Sah, A.; Rawat, S.; Choudhury, T.; Khanna, A. Block Chain Platforms and Smart Contracts. In Blockchain Applications in IoT Ecosystem; Springer: Cham, Switzerland, 2021; pp. 65-76.

66. Oliveira, T.A.; Oliver, M.; Ramalhinho, H. Challenges for Connecting Citizens and Smart Cities: ICT, E-Governance and Blockchain. Sustainability 2020, 12, 2926. [CrossRef]

67. Wang, H.; Qin, H.; Zhao, M.; Wei, X.; Shen, H.; Susilo, W. Blockchain-based fair payment smart contract for public cloud storage auditing. Inf. Sci. 2020, 519, 348-362. [CrossRef]

68. Mora, H.; Mendoza-Tello, J.C.; Varela-Guzmán, E.G.; Szymanski, J. Blockchain technologies to address smart city and society challenges. Comput. Hum. Behav. 2021, 122, 106854. [CrossRef]

69. Paul, R.; Ghosh, N.; Sau, S.; Chakrabarti, A.; Mohapatra, P. Blockchain based secure smart city architecture using low resource IoTs. Comput. Networks 2021, 196, 108234. [CrossRef]

70. Nguyen, D.C.; Pathirana, P.N.; Ding, M.; Seneviratne, A. Blockchain for 5G and beyond networks: A state of the art survey. J. Netw. Comput. Appl. 2020, 166, 102693. [CrossRef]

71. Esmat, A.; de Vos, M.; Ghiassi-Farrokhfal, Y.; Palensky, P.; Epema, D. A novel decentralized platform for peer-to-peer energy trading market with blockchain technology. Appl. Energy 2021, 282, 116123. [CrossRef]

72. Guo, J.; Ding, X.; Wu, W. A Blockchain-Enabled Ecosystem for Distributed Electricity Trading in Smart City. IEEE Internet Things J. 2020, 8, 2040-2050. [CrossRef]

73. Said, D. A Decentralized Electricity Trading Framework (DETF) for Connected EVs: A Blockchain and Machine Learning for Profit Margin Optimization. IEEE Trans. Ind. Informatics 2020, 17, 6594-6602. [CrossRef]

74. Swain, A.; Salkuti, S.; Swain, K. An Optimized and Decentralized Energy Provision System for Smart Cities. Energies 2021, 14, 1451. [CrossRef]

75. Li, Z.; Kang, J.; Yu, R.; Ye, D.; Deng, Q.; Zhang, Y. Consortium Blockchain for Secure Energy Trading in Industrial Internet of Things. IEEE Trans. Ind. Inform. 2017, 14, 3690-3701. [CrossRef]

76. Gai, K.; Wu, Y.; Zhu, L.; Qiu, M.; Shen, M. Privacy-Preserving Energy Trading Using Consortium Blockchain in Smart Grid. IEEE Trans. Ind. Informatics 2019, 15, 3548-3558. [CrossRef]

77. Wang, S.; Taha, A.F.; Wang, J.; Kvaternik, K.; Hahn, A. Energy Crowdsourcing and Peer-to-Peer Energy Trading in BlockchainEnabled Smart Grids. IEEE Trans. Syst. Man. Cybern. Syst. 2019, 49, 1612-1623. [CrossRef]

78. Wang, Z.; Luo, N.; Zhou, P. GuardHealth: Blockchain empowered secure data management and Graph Convolutional Network enabled anomaly detection in smart healthcare. J. Parallel Distrib. Comput. 2020, 142, 1-12. [CrossRef]

79. Hasavari, S.; Song, Y.T. A secure and scalable data source for emergency medical care using blockchain technology. In Proceedings of the IEEE 17th International Conference on Software Engineering Research, Management and Applications (SERA), Honolulu, HI, USA, 29-31 May 2019; pp. 71-75.

80. Sharma, A.; Tomar, R.; Chilamkurti, N.; Kim, B.-G. Blockchain Based Smart Contracts for Internet of Medical Things in eHealthcare. Electronics 2020, 9, 1609. [CrossRef]

81. Javed, I.T.; Alharbi, F.; Bellaj, B.; Margaria, T.; Crespi, N.; Qureshi, K.N. Health-ID: A Blockchain-Based Decen-tralized Identity Management for Remote Healthcare. Healthcare 2021, 9, 712. [CrossRef]

82. Celesti, A.; Ruggeri, A.; Fazio, M.; Galletta, A.; Villari, M.; Romano, A. Blockchain-Based Healthcare Workflow for Tele-Medical Laboratory in Federated Hospital IoT Clouds. Sensors 2020, 20, 2590. [CrossRef]

83. Agbo, C.C.; Mahmoud, Q.H.; Eklund, J.M. Blockchain Technology in Healthcare: A Systematic Review. Healthcare 2019, 7, 56. [CrossRef]

84. Fusco, A.; Dicuonzo, G.; Dell'Atti, V.; Tatullo, M. Blockchain in Healthcare: Insights on COVID-19. Int. J. Environ. Res. Public Health 2020, 17, 7167. [CrossRef]

85. Qiu, J.; Liang, X.; Shetty, S.; Bowden, D. Towards Secure and Smart Healthcare in Smart Cities Using Blockchain. In Proceedings of the 2018 IEEE International Smart Cities Conference (ISC2), Kansas City, MO, USA, 16-19 September 2018; IEEE: Manhattan, NY, USA, 2018; pp. 1-4.

86. Daramola, O.; Thebus, D. Architecture-Centric Evaluation of Blockchain-Based Smart Contract E-Voting for National Elections. Informatics 2020, 7, 16. [CrossRef] 
87. Bulut, R.; Kantarc1, A.; Keskin, S.; Bahtiyar, Ş. Blockchain-based electronic voting system for elections in Turkey. In Proceedings of the 4th International Conference on Computer Science and Engineering (UBMK), Samsun, Turkey, 11-15 September 2019 ; pp. $183-188$.

88. Taş, R.; Tanrıöver, Ö.Ö. A Systematic Review of Challenges and Opportunities of Blockchain for E-Voting. Symmetry 2020, 12, 1328. [CrossRef]

89. Zhang, S.; Wang, L.; Xiong, H. Chaintegrity: Blockchain-enabled large-scale e-voting system with robustness and universal verifiability. Int. J. Inf. Secur. 2019, 19, 323-341. [CrossRef]

90. Hanifatunnisa, R.; Rahardjo, B. Blockchain based e-voting recording system design. In Proceedings of the 201711 th International Conference on Telecommunication Systems Services and Applications (TSSA), Lombok, Indonesia, 26-27 October 2017; IEEE: Manhattan, NY, USA, 2017; pp. 1-6.

91. Hackius, N.; Petersen, M. Blockchain in logistics and supply chain: Trick or treat. In Digitalization in Supply Chain Management and Logistics: Smart and Digital Solutions for an Industry 4.0 Environment, Proceedings of the Hamburg International Conference of Logistics (HICL), Hamburg, Germany, 25-27 September 2017; Epubli: Berlin, Germany, 2017; Volume 23, pp. 3-18.

92. Francisco, K.; Swanson, D. The Supply Chain Has No Clothes: Technology Adoption of Blockchain for Supply Chain Transparency. Logistics 2018, 2, 2. [CrossRef]

93. Tian, F. An agri-food supply chain traceability system for China based on RFID \& blockchain technology. In Proceedings of the 2016 13th International Conference on Service Systems and Service Management (ICSSSM), Kunming, China, $24-26$ June 2016. [CrossRef]

94. Saberi, S.; Kouhizadeh, M.; Sarkis, J.; Shen, L. Blockchain technology and its relationships to sustainable supply chain management. Int. J. Prod. Res. 2019, 57, 2117-2135. [CrossRef]

95. Schmidt, C.G.; Wagner, S.M. Blockchain and supply chain relations: A transaction cost theory perspective. J. Purch. Supply Manag. 2019, 25. [CrossRef]

96. Duan, J.; Zhang, C.; Gong, Y.; Brown, S.; Li, Z. A Content-Analysis Based Literature Review in Blockchain Adoption within Food Supply Chain. Int. J. Environ. Res. Public Health 2020, 17, 1784. [CrossRef]

97. Clauson, K.A.; Breeden, E.A.; Davidson, C.; Mackey, T.K. Leveraging Blockchain Technology to Enhance Supply Chain Management in Healthcare: An exploration of challenges and opportunities in the health supply chain. Blockchain Healthc. Today 2018, 1, 1-12. [CrossRef]

98. Rejeb, A.; Keogh, J.G.; Treiblmaier, H. Leveraging the Internet of Things and Blockchain Technology in Supply Chain Management. Futur. Internet 2019, 11, 161. [CrossRef]

99. Sladić, G.; Milosavljević, B.; Nikolić, S.; Sladić, D.; Radulović, A. A Blockchain Solution for Securing Real Property Transactions: A Case Study for Serbia. ISPRS Int. J. Geo-Information 2021, 10, 35. [CrossRef]

100. Hoxha, V.; Sadiku, S. Study of factors influencing the decision to adopt the blockchain technology in real estate transactions in Kosovo. Prop. Manag. 2019, 37, 684-700. [CrossRef]

101. Veuger, J. Trust in a viable real estate economy with disruption and blockchain. Facilities 2018, 36, 103-120. [CrossRef]

102. Wouda, H.P.; Opdenakker, R. Blockchain technology in commercial real estate transactions. J. Prop. Invest. Financ 2019, 37, 570-579. [CrossRef]

103. Dijkstra, M. Blockchain: Towards Disruption in the Real Estate Sector: An Exploration on the Impact of Blockchain Techno. Master's Thesis, Delft University of Technology, Delft, The Netherlands, 2017.

104. Garcia-Teruel, R.M. Legal challenges and opportunities of blockchain technology in the real estate sector. J. Prop. Plan. Environ. Law 2020, 12, 129-145. [CrossRef]

105. Shuaib, M.; Alam, S.; Daud, S.M. Improving the Authenticity of Real Estate Land Transaction Data Using Blockchain-Based Security Scheme. In Proceedings of the International Conference on Advances in Cyber Security, Penang, Malaysia, 8-9 December 2020; Springer: Singapore, 2020; pp. 3-10.

106. Scopus. Available online: https://www.scopus.com (accessed on 1 August 2021). 